\title{
The Utility of the REM Latency Test in Psychiatric Diagnosis: A Study of 81 Depressed Outpatients
}

\author{
Hagop S. Akiskal, Helio Lemmi, Boghos Yerevanian, Doug King, and \\ Joe Belluomini
}

Received December 28, 1981; revised version received April 12, 1982; accepted May 7, 1982.

\begin{abstract}
To examine the utility of the REM (rapid eye movement) latency test in identifying outpatient primary depressions, 81 consecutive referrals to a sleep disorders center were evaluated in a phenomenologic, sleep polygraphic, and psychometric study. Modified Feighner (St. Louis) diagnoses were definite primary depression $(n=19)$, probable primary depression $(n=30)$, depression chronologically secondary to preexisting psychiatric disorders $(n=19)$, and nonaffective psychiatric disorder $(n=13)$. There were 18 nonpsychiatric controls. REM latency less than 70 minutes on 2 consecutive nights detected $62 \%$ of primary depressions, discriminating them from the other diagnostic groups with $88 \%$ specificity. There were no false positives among controls. These data provided a $90 \%$ confidence for the diagnosis of primary depression in this outpatient sample. Requiring 2 consccutive nights of shortened REM latency appears to improve significantly the specificity of a test previously considered to have high sensitivity but relatively low specificity for depressive disorders.
\end{abstract}

Key Words. REM latency, biologic marker, primary and secondary depression, melancholia.

Strategies for developing biological tests for psychiatric disorders are of major current clinical research interest (Akiskal, 1978, 1980; Carroll, 1980). Much of this effort has focused on affective illness, where the most promising results have been obtained. Among the markers currently under investigation, the dexamethasone suppression (Carroll et al., 1981) and REM (rapid eye movement) latency (Kupfer, 1976) tests have emerged as the most consistently positive.

In a series of pioneering studies in inpatients, Kupfer and associates have presented evidence that REM latency - the time elapsed from slcep onset to the first REM period-is significantly shortened in primary compared with secondary depressions. The mean figures are 38 minutes for the primary, and 72 minutes for the secondary group (Kupfer et al., 1978); the grand mean of normal control subjects for adult age

\footnotetext{
Hagop S. Akiskal, M.D., is Research Psychiatrist, Helio Lemmi, M.D., is Director, and Joe Belluomini is Technical Director, Sleep Disorders Center, Laboratory of Neurophysiology, Baptist Memorial Hospital, Memphis, TN. Also, Dr. Akiskal is Professor of Psychiatry, Associate Professor of Pharmacology, and Director of the Affective Disorders Program, and Dr. Lemmi is Clinical Professor of Neurology at the University of Tennessee College of Medicine, Memphis. Boghos Yerevanian, M.D., is Assistant Professor of Psychiatry and Director of the Affective Disorders Unit, Department of Psychiatry, University of Rochester, Rochester, NY. Doug King, M.D., is Assistant Professor of Psychiatry and Director of the Inpatient Program of the Clinical Studies Unit, Department of Psychiatry, University of Michigan, Ann Arbor, MI. At the time of this study, Drs. Yerevanian and King were Residents in Psychiatry at the University of Tennessee. (Reprint requests to Dr. H.S. Akiskal, UT Dept. of Psychiatry, Ste. 633, 66 N. Pauline St., Memphis, TN 38163, U.S.A.)
} 
groups is 90 minutes (Williams et al., 1974). These studies have used the St. Louis diagnostic criteria (Feighner et al., 1972), which define primary depression as occurring in the absence of preexisting diagnosable mental disorders considered validated in followup studies. Many, but not all, of these patients would probably meet the criteria for endogenous depression (Research Diagnostic Criteria; Spitzer et al., 1978) or melancholia (DSM-III. American Psychiatric Association, 1980). By contrast, secondary depressions occur in the setting of preexisting nonaffective psychiatric disorders and usually lack melancholic features (Akiskal et al., 1978, 1979).

Different results have been reported in studies using more broadly defined Research Diagnostic Criteria depressive subtypes. For instance, Rush et al. (1982), who reported on outpatients, found that REM latency was useful in discriminating endogenous from nonendogenous, but not primary from secondary depressives. These results were further supported by the dexamethasone suppression test, as originally reported by Carroll et al. (1980). In both sets of studies, depressed patients with history of alcoholism or drug abuse were classified as secondary depressives. However, recent clinical experience (Feighner, oral communication, 1980) indicates that substance use disorders often complicate the early course of primary mood disorders. In line with this suggestion, the electroencephalographic (EEG) sleep findings of Kupfer's group were replicated in a preliminary report on a small sample of chronic depressives in which drug dependence and alcoholism were not an exclusion criterion for the primary depressive diagnoses (Yerevanian and Akiskal, 1979). Similar results were obtained when Rush et al. (1982) rcanalyzed thcir data on a small subsample of depressives without substance use disorders.

The purpose of the present study was to evaluate further, in a large outpatient sample, the diagnostic utility of the REM latency test in distinguishing primary depressions from depressions occurring in the context of nonaffective disorders. In particular, we intended to limit secondary depressions to a more rigorously defined group of disorders than in previous studies, and wished to develop psychometric strategies for improving the specificity of the test for primary depressions.

\section{Methods}

Diagnostic Groups and Controls. The study groups consisted of 81 consecutive private outpatients referred to the Sleep Disorders Center. Psychiatric diagnoses were obtained through semistructured interviews based on the St. Louis scheme (Feighner et al., 1972). Criteria for definite primary depression were: (1) dysphoric mood change and at least five classic depressive symptoms sustained for at least 4 weeks, (2) absence of grief or toxic factors known to simulate depression, and (3) no preexisting nonaffective psychiatric disorder from the modified Feighner list. (As noted previously, alcoholism and drug dependence were not considered exclusion conditions for a primary depressive diagnosis.) Probable primary depression was defined as occurring in the absence of reported subjective dysphoria or with four symptoms only. Secondary depression was diagnosed when the full depressive syndrome occurred in the setting of nonaffective psychiatric disorders such as anxiety (panic disorder in $D S M-I I I$ ), phobic and obsessive-compulsive disorders, Briquet's (somatization in DSM-III) disorder, sociopathy, ego-dystonic homosexuality, transsexualism, anorexia nervosa, schizophrenia, organic brain syndrome, and mental retardation. Nonaffective psychiatric disorders comprised the aforementioncd conditions in the absence of a concurrent affective syndrome.

The 18 nonpsychiatric control subjects, chosen from the same setting, were either noncase $(n=9)$ or medically ill $(n=9)$ outpatients with no evidence of psychiatric disorder. The medical 
disorders included diabetes mellitus ( $n=3)$, seizure disorder $(n=2)$, sickle cell anemia $(n=2)$, Pelizaeus Merzbacher disease $(n=1)$, and rheumatoid arthritis $(n=1)$.

Procedure. The routine clinical procedure in our laboratory consists of (1) a period of at least 14 days free of psychoactive drugs (except for "stable" nicotine and caffeine intake); (2) full medical and neurological history and exam; (3) routine chemistry and EEG; (4) comprehensive sleep history based on the Stanford sleep questionnaire; (5) the Minnesota Multiphasic Personality Inventory (MMPI) and the Beck Depression Inventory (BDI); (6) formal psychiatric evaluation conducted blind to sleep polygraphy; (7) at least 2 consecutive nights of sleep polysomnographic study consisting of continuous EEG, horizontal electrooculogram (EOG), and submental electromyogram; and (8) scoring of sleep records according to the manual of Rechtschaffen and Kales (1968). REM latency reported in this article was scored from the onset of the first stage 2 (to the first REM period) if stage 2 met the requirements as set forth by Rechtschaffen and Kales and had not been interrupted by stage 1 or waking state for a duration of 3 or more minutes; wake time after stage 2 was not subtracted and, ordinarily, 3 minutes of REM were required.

Statistical Techniques. Means for age, sex ratio, BDI scores, and the shortest REM latency on any night of study were compared by analysis of variance. Because REM latency is reported to be significantly shorter on nonadaptation compared to first or adaptation nights in sccondary depressives (Coble et al., 1976), the shortest score (rather than the mean score of all nights of study) was used to minimize differences between groups and to provide a more stringent test of the hypothesis that depressions secondary to nonaffective psychiatric disorders are different from primary depressions.

Correlations of age and BDI scores with REM latency were determined by the Spearman rank coefficient $(r s)$. The diagnostic utility of REM latency (RL) was computed as follows (Vecchio, 1966):

\begin{tabular}{|c|c|}
\hline Sensitivity $(\%)=$ & $n(\mathrm{RL}$ scores $<$ cutoff in depressed group) \\
\hline & Total $n$ (depressed group) \\
\hline Specificity $(\%)=$ & $n$ (RL scores $>$ cutoff in reference group) \\
\hline & Total $n$ (reference group) \\
\hline Confidence level $(\%)=$ & $n$ (RL scores $<$ cutoff in depressed group) \\
\hline
\end{tabular}

Two different REM latency cutoff scores were used in the above computations. The first was derived from the lower tail of the $95 \%$ confidence limit in the control group ( $\bar{X}$ controls $-1.96 \mathrm{SD})$. The second cutoff was somewhat arbitrarily set at REM latency $<70$ minutes, based on the lower limit of published norms most often quoted in the literature (Williams et al., 1974).

\section{Results}

Diagnostic Groups. The entire sample was nonpsychotic and all but four depressives were unipolar. Nineteen patients were diagnosed as definite primary and 30 as probable primary depression. In the probable group 17 patients had affective manifestations that were intermittent and subsyndromal; the remaining 13 presented with prominent somatic complaints such as insomnia, fatigue, hypersomnia, or impotence, but denied subjectively experienced dysphoric mood.

The secondary depression group comprised 19 patients whose illness chronologically followed panic or agoraphobic $(n=10)$, obsessive-compulsive $(n=3)$ and somatization $(n=5)$ disorders, and sociopathy $(n=1)$. 
Almost two-thirds of each of the above groups reported history of some form of substance use, most commonly sedative-hypnotic drugs.

The nonaffective psychiatric group included 13 patients with miscellaneous psychiatric diagnoses who did not meet the St. Louis Criteria for probable or definite primary depression. These diagnoses were somatization $(n=6)$, panic $(n=3)$, obsessive-compulsive $(n=1)$, phobic $(n=1)$, generalized anxiety $(n=1)$, and antisocial personality $(n=1)$ disorders.

Demographic and Clinical Characteristics. Almost all subjects belonged to the Hollingshead-Redlich (1958) classes II and III. There was a nonsignificant trend for controls to be on the average 10 years younger than the study groups (Table 1). There was also a nonsignificant trend of male preponderance in all groups but secondary depressives.

Table 1. Mean ( \pm SD) for age, sex ratio, and BDI score in study and control groups

\begin{tabular}{|c|c|c|c|c|c|c|}
\hline \multirow[b]{2}{*}{ Variables } & \multicolumn{2}{|c|}{ Primary depression } & \multirow{2}{*}{$\begin{array}{c}\text { Secondary } \\
\text { depression } \\
(n=19)\end{array}$} & \multirow{2}{*}{$\begin{array}{c}\text { Nonaffective } \\
\text { psychiatric } \\
\text { disorders } \\
(n=13)\end{array}$} & \multirow[b]{2}{*}{$\begin{array}{l}\text { Controls } \\
(n=18)\end{array}$} & \multirow[b]{2}{*}{$p$} \\
\hline & $\begin{array}{l}\text { Definite } \\
(n=19)\end{array}$ & $\begin{array}{c}\text { Probable } \\
(n=30)\end{array}$ & & & & \\
\hline Age & $42.7 \pm 13.4$ & $44.1 \pm 15.5$ & $41.8 \pm 11.5$ & $42.6 \pm 13.4$ & $32.6 \pm 14.0$ & NS \\
\hline Sex ratio & 1.4 & 1.5 & 1.6 & 1.2 & 1.3 & NS \\
\hline BDI score & $12.3 \pm 4.3$ & $11.0 \pm 9.2$ & $16.4 \pm 10.2$ & $10.0 \pm 8.3$ & $1.8 \pm 1.5$ & $<0.011$ \\
\hline
\end{tabular}

1. Controls significantly lower than other groups.

The four study groups did not significantly differ in BDI scores, with mean scores just above the lowest cutoff for clinical depression set for this instrument (Beck et al., 1961). As expected, the control group had a significantly lower mean BDI score compared with the four study groups.

The sex ratio and $\mathrm{BDI}$ findings, coupled with the fact that almost half of the depressed sample ( 30 out of 68 ) met criteria for only probable depression, suggest that this is a special cohort of outpatient depressives. Compared with the typical psychiatric outpatient depressive, these patients are more likely to be male, to present with somatic complaints, to suffer from subsyndromal intensity of illness, to deny subjective mood change, and therefore to have relatively low scores on the "cognitively loaded" Beck inventory. Furthermore, their course tended to be intermittently chronic rather than episodic.

REM Latency. The Newman Keuls test indicates that the definite and probable primary depressive groups had similar REM latencies (combined mean $\pm \mathrm{SD}=51.1 \pm$ 15) that were significantly shorter than those for the remaining groups (Fig. 1). The mean $( \pm$ SD) REM latency for secondary depressions $(75.9 \pm 24.7)$ did not differ significantly from that for nonaffective psychiatric disorders $(76.5 \pm 15.8)$ or nonpsychiatric controls $(91.1 \pm 19.1)$. These findings were upheld when the more conservative Scheffé test was applied $(p<0.05)$. 
Fig. 1. REM latency comparison of depressive subtypes and controls

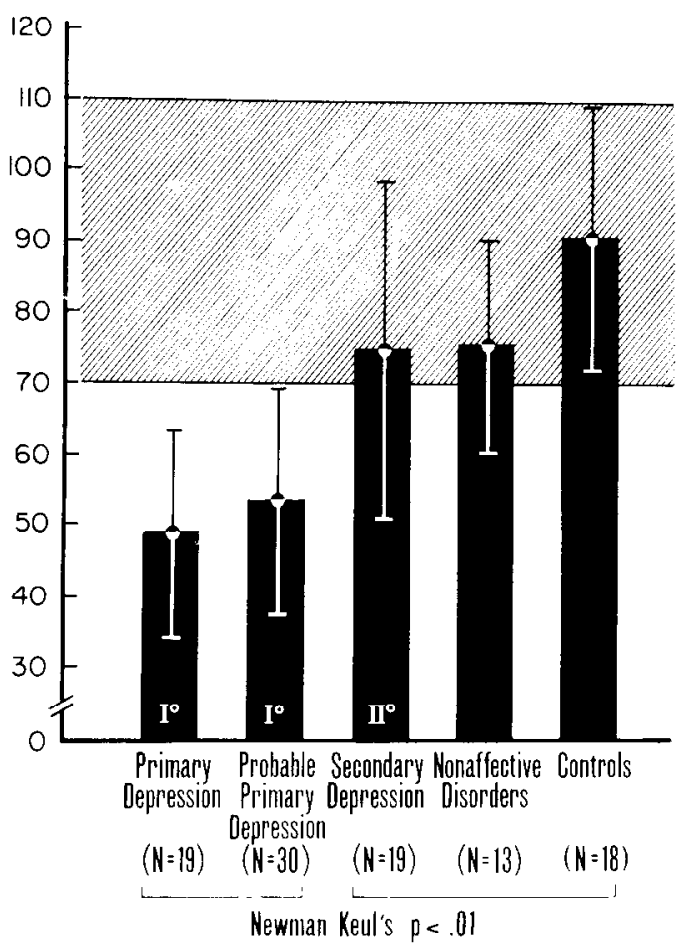

The hatched area is the "normal range" of REM latencies.

Correlations Between REM Latency, Age, and BDI Scores. Spearman rank correlations between REM latency and age were nonsignificant within each group and for combined depressive groups $\left(r_{\mathrm{s}}=-0.06\right)$ or all groups $\left(r_{\mathrm{s}}=-0.05\right)$. This finding in mild depressives is to be contrasted to that of a study by the Pittsburgh group (Ulrich et al., 1980) showing an inverse relationship between age and REM latency in a severely ill group of depressives, but is in accordance with Rush et al. (1982) who also studied outpatients.

The correlation between REM latency and BDI scores within each depressive group and all depressive groups combined was nonsignficant $\left(r_{\mathrm{s}}=-0.03\right)$. However, as expected, there was a modest negative correlation between REM latency and BDI scores for all groups $\left(r_{\mathrm{s}}=-0.28, p<0.05\right)$, largely due to a gradient in scores between depressive (primary, probable primary, and secondary) and nondepressive (nonaffective psychiatric and nonpsychiatric control) groups.

Sensitivity, Specificity, and Diagnostic Confidence. In these computations, probable and definite depressions were combined into a single primary group. The category designated "all depressions" includes primary and secondary depressions. 
As shown in Table 2, the cutoff score based on the $95 \%$ lower confidence limit of control subjects $(<52$ minutes) yields a low sensitivity and high specificity for the diagnosis of depression. The converse is true for the cutoff based on published norms $(<70$ minutes), which yields high sensitivity and relatively low specificity. The 70-minute cutoff provides the more useful measure for clinical purposes, i.e., it detects the largest number of depressives, with an acceptable degree of specificity for depressive diagnoses. What is disturbing, however, is that these computations based on the night with the lowest REM latency do not indicate diagnostic selectivity of REM latency for the primary group.

$\begin{aligned} & \text { Table 2. Sensitivities and specificities of two cutoff REM } \\
& \text { latencies in outpatient depressives }\end{aligned}$
\begin{tabular}{lcc} 
REM latency & Sensitivity (\%) & Specificity (\%) \\
\hline Less than 52 minutes & & \\
Probable and definite depressions & 44 & 94 \\
All depressions & 34 & 92 \\
Less than 70 minutes & & \\
Probable and definite depressions & 96 & 59 \\
All depressions & 82 & 69 \\
\hline
\end{tabular}

1. Lowest value of any night per patient.

For this reason, we examined the discriminatory power of different nights of REM latency less than 70 minutes (Table 3). When lowest REM latency of any night is considered, the sensitivity is $96 \%$, and specificity $59 \%$; furthermore, $11 \%$ of controls are misidentified as depressed, giving a confidence level of $73 \%$ for the diagnosis of depression. However, no patients without affective disorder are selected $(0 \%$ rate of false positives) when either the first or two consecutive nights are considered.

Table 3. Diagnostic value of REM latency $<70$ for primary depressions vs. secondary depressions, nonaffective psychiatric disorders, and nonpsychiatric controls

\begin{tabular}{lccc}
\hline Measure & Any night & First night & Consecutive nights \\
\hline Sensitivity $(\%)$ & 96 & 59 & 62 \\
Specificity $(\%)$ & 59 & 81 & 88 \\
False positives & & & 0 \\
in controls $(\%)$ & 11 & 83 & 90 \\
Confidence level $(\%)$ & 73 & & \\
\hline
\end{tabular}

Although the mean REM latency of secondary depressives was significantly higher than that of primary depressives, $47 \%$ of the secondary depressives had at least 1 night with a value shorter than 70 minutes. However, only $21 \%$ of secondary depressives had 
such an abnormally low value on the first night. The corresponding figures for primary depressions are $95 \%$ and $58 \%$, respectively. This relative absence of an adaptation night effect on the REM latency of primary versus secondary depressives (significant at the $p<0.01$ level) has also been observed by Kupfer et al. (1978). In other words, an incidental night of shortened REM latency seems to have little diagnostic significance for primary depression; by contrast, shortening on 2 consecutive nights, especially on the first and second nights, may be indication of "autonomy" of the depression or its independence from environmental factors in the sleep laboratory, and appears highly specific for primary depression. Use of the cutoff REM latency $<70$ minutes on 2 consecutive nights seems to provide the best confidence level $(90 \%)$ with a high specificity $(88 \%)$ and acceptable sensitivity $(62 \%)$. This criterion, which detects twothirds of primary depressions, occurs rarely in secondary depressions or other psychiatric disorders and normals, and-in this heterogeneous outpatient population that includes depressive, nonaffective psychiatric, and medical disorders, as well as normal individuals-lends $90 \%$ confidence to the diagnosis of primary depression.

\section{Discussion}

The criteria for endogenous or melancholic depression are more restrictive than those for primary depression (Nelson and Charney, 1980, 1981). Their application to inpatient populations will help in identifying a core group of affective probands for clinical work or research. However, many outpatient depressives do not fit a clear-cut endogenous pattern (Akiskal et al., 1978). The criteria for primary depression-which select a broad group of depressives - may therefore be more appropriate in outpatient studies.

The findings of the present study indicate that REM latency in our outpatient depressive sample with milder forms of illness is dependent on neither age nor scores obtained on a "cognitively loaded" depression inventory. Thus, in our sample, the correlation of REM latency was with a categorical diagnosis of primary depression rather than a dimension of depression measured on the Beck instrument. Furthermore, the fact that depressions in the context of nonaffective disorders meet the criteria for depression at a syndromal level, yet have mean REM latencies not significantly different from nondepressed psychiatric, medical, or noncase subjectsin contrast to syndromal or subsyndromal primary depressions--suggests that a qualitative difference exists between primary and secondary depressions.

One implication of these results is that diagnostic assignment of patients to criteriabased depressive groups should be coupled with a clinical diagnosis (Carroll et al., 1980). By analogy with the Aristotelian system (Russell, 1959), wherein certain attributes like color can only be defined by pointing at them, a total gestalt of "real" depression can be best detected, at least at this stage of the art, by experienced clinicians. It is not just the presence of anhedonia, psychomotor retardation, or other signs and symptoms, but the special patterning of these individual manifestations taken together that constitutes clinical depression.

The translation of this clinical art to a science of diagnosis is particularly difficult in mild outpatient depressions. It is therefore encouraging that our REM latency data supported the chronological principle (Feighner et al., 1972) - the presence or absence 
of preexisting validated nonaffective diagnoses-provided alcoholism and drug dependence are excluded. Our data lend biologic validity to the concept of primary depression as modified by us, previously validated by longitudinal course (Murphy et al., 1974) and family history (Akiskal et al., 1979).

Furthermore, the results of the present investigation extended Kupfer's (1976) findings to the mild end of the depressive spectrum. As we have argued elsewhere (Akiskal et al., 1980), it may be that many of our probable primary depressive probands suffer from "submelancholic" illnesses not easily diagnosed by clinical intuition alone. This consideration illustrates the value of biologic markers in subtle clinical diagnostic decisions in the area of affective disorders (Akiskal, 1978, 1980, 1981) as well as the importance of broad diagnostic criteria for depression in defining the nosologic borders of primary affective illness. In other words, restricting the concept of depressive illness to endogenous or melancholic depression is useful in developing diagnostic biologic tests, and "broad" concepts such as those of primary depression are required in studies that attempt to extend these tests in defining the full range of the depressive spectrum.

Finally, the present study suggests that the specificity of REM latency as a diagnostic test can be enhanced by considering data from 2 consecutive nights. Gillin et al. (1979), who averaged data from nonadaptation nights, recently pointed out that REM latency was sensitive in detecting depression but not specific enough to separate it from nondepression; they achieved greater discrimination by multivariate analysis involving many sleep measures in addition to REM latency. Feinberg et al. (1982), who derived discriminant functions based on data from Gillin's laboratory, could achieve a specificity of $93 \%$ in separating endogenous from nonendogenous depressions by using the joint predictive power of REM latency and REM density. Our approach based on 2 consecutive nights extends the strategy of Kupfer's group in providing a higher level of specificity for REM latency for primary depression than hitherto achieved by considering data from nonadaptation nights (whether single nights or averaged).

\section{Conclusion}

Mild depressive states seen in the outpatient setting can present as primary affective disorders or develop in the context of validated nonaffective psychiatric illnesses such as panic, agoraphobic, obsessive-compulsive, somatization, and sociopathic disorders. Except for chronology, these patients seem to have similar depressive symptoms. Yet, biologically - in this study with respect to REM latency - the mean values for this sleep neurophysiologic parameter are significantly different in the primary group. Clinically these patients can be described as "submelancholic," yet detection of a melancholic quality is not easily made on clinical grounds in this population situated at the mild end of the depressive spectrum. REM latency shorter than 70 minutes on 2 consecutive nights correctly identifies $62 \%$ of primary depressives, with a specificity of $88 \%$, and a diagnostic confidence of $90 \%$. Along with neuroendocrine tests for psychiatric diagnosis, sleep polygraphic findings provide the hope that valid and reliable biological tests are finally becoming available to psychiatric practice. As Carroll et al. (1981) have pointed out, these test matrices are at least comparable, if not superior, to those of routinely used diagnostic tests in nonpsychiatric medical practice. 
Acknowledgment. Sharon Burt, Lisa Milligan, and Phil Vance assisted with technical recordings. Dr. Ted Rosenthal provided statistical, and Christy Wright, editorial assistance. The writing of this article was supported in part by the State of Tennessee, Department of Mental Health and Mental Retardation, and USPHS MH-05931 from the National Institute of Mental Health, Rockville, MD.

\section{References}

Akiskal, H.S. The joint use of clinical and biological criteria for psychiatric diagnosis: I. A historical and methodological review. In: Akiskal, H.S., and Webb, W.L., eds. Psychiatric Diagnosis: Exploration of Biological Predictors. Spectrum, New York, p. 103 (1978).

Akiskal, H.S. External validating criteria for psychiatric diagnosis: Their application in affective disorders. Journal of Clinical Psychiatry, 41, 6 (1980).

Akiskal, H.S. Subaffective disorders: Dysthymic, cyclothymic and bipolar II disorders in the "borderline" realm. Psychiatric Clinics of North America, 4, 25 (1981).

Akiskal, H.S., Bitar, A.H., Puzantian, V.R., Rosenthal, T.L., and Walker, P.W. The nosological status of neurotic depression: A prospective three-to-four year examination in light of the primary-secondary and unipolar-bipolar dichotomies. Archives of General Psychiatry. 35, 756 (1978).

Akiskal, H.S., Rosenthal, T.L., Haykal, R.F., Lemmi, H., Rosenthal, R.H., and Scott-Strauss, A. Characterological depressions: Clinical and sleep EEG findings separating "subaffective dysthymics" from "character-spectrum disorders." Archives of General Psychiatry, 37, 777 (1980).

Akiskal, H.S., Rosenthal, R.H., Rosenthal, T.L., Kashgarian, M., Khani, M.K., and Puzantian, V.R. Differentiation of primary affective illness from situational, symptomatic and secondary depressions. Archives of General Psychiatry, 36, 635 (1979).

American Psychiatric Association. DSM-III: Diagnostic and Statistical Manual of Mental Disorders. 3rd ed. APA, Washington, DC (1980).

Beck, A.T., Ward, C.H., Mendelson, M., Mock, J.E., and Erbaugh, J.K. An inventory for measuring depression. Archives of General Psychiatry, 4, 561 (1961).

Carroll, B. Implications of biological research for the diagnosis of depression. In: Mendlewicz, J., ed. New Advances in the Diagnosis and Treatment of Depressive Illness. Excerpta Medica, Amsterdam, p. 85 (1980).

Carroll, B.J., Feinberg, M., Greden, J.F., Haskett, R.F., James, N.Mcl., Steiner, M., and Tarika, J. Diagnosis of endogenous depression: Comparison of clinical, research and neuroendocrine criteria. Journal of Affective Disorders, 2, 177 (1980).

Carroll, B.J., Feinberg, M., Greden, J.F., Tarika, J., Albala, A.A., Haskett, R.F., James, N.Mcl., Kronfol, Z., Lohr, N., Steiner, M., de Vigne, J.P., and Young, E. A specific laboratory test for the diagnosis of melancholia: Standardization, validation and clinical utility. Archives of General Psychiatry, 38, 15 (1981).

Coble, P., Foster, F.G., and Kupfer, D.J. EEG sleep diagnosis of primary depression. Archives of General Psychiatry, 33, 1124 (1976).

Feighner, J.P., Robins, E., Guze, S.B., Woodruff, R.A., Winokur, G., and Munoz, R. Diagnostic criteria for use in psychiatric research. Archives of General Psychiatry, 26, 57 (1972).

Feinberg, M., Gillin, J.C., Carroll, B.J., Greden, J.F., and Zis, A.P. EEG studics of slecp in the diagnosis of depression. Biological Psychiatry, 17, 305 (1982).

Gillin, J.C., Duncan, W., Pettigrew, K.D., Frankel, B.L., and Snyder, F. Successful separation of depressed, normal, and insomniac subjects by EEG sleep data. Archives of General Ps.ychiatry, 36, 85 (1979).

Hollingshead, A.B., and Redlich, F.C. Social Class and Mental Illness. John Wiley \& Sons, New York (1958).

Kupfer, D.J. REM latency: A psychobiological marker for primary depressive disease. Biological Psychiatry, 11, 159 (1976).

Kupfer, D.J., Foster, G.F., Coble, P., McPartland, R.J., and Ulrich, R.F. The application of EEG sleep for the differential diagnosis of affective disorders. American Journal of Psychiatr. 135, 69 (1978). 
Murphy, G.E., Woodruff, R.A., Herjanic, M., and Fisches, J.R. Validity of the diagnosis of primary affective illness: A prospective study with a five year follow-up. Archives of General Psychiatry, 30, 751 (1974).

Nelson, J.C., and Charney, D.S. Primary affective disorder criteria and the endogenousreactive distinction. Archives of General Psychiatry, 37, 787 (1980).

Nelson, J.C., and Charney, D.S. The symptoms of major depressive illness. American Journal of Psychiatry, 138, 1 (1981).

Rechtschaffen, A., and Kales, A., eds. A Manual of Standardized Terminology, Techniques and Scoring System for Sleep Stages of Human Subjects. National Institutes of Health Publication No. 204. Superintendent of Documents, U.S. Government Printing Office, Washington, DC (1968).

Rush, J., Giles, D.E., Roffwarg, H.P., and Parker, C.R. Sleep EEG and dexamethasone suppression test findings in outpatients with unipolar major depressive disorder. Biological Psychiatry, 17, 327 (1982).

Russell, B. Wisdom of the West. Macdonald, London, p. 48 (1959).

Spitzer, R., Endicott, J., and Robins, E. Research Diagnostic Criteria: Rationale and reliability. Archives of General Psychiatry, 35, 773 (1978).

Ulrich, R.F., Shaw, D.H., and Kupfer, D.J. Effects of aging on EEG sleep in depression. Sleep, 3, 31 (1980).

Vecchio, T.J. Predictive value of simple diagnostic test in unselected populations. New England Journal of Medicine, 274, 1171 (1966).

Williams, R.L., Karacan, J., and Hursch, C.J. EEG of Human Sleep: Clinical Applications. Wiley, New York (1974).

Yerevanian, B.I., and Akiskal, H.S. Neurotic, characterological and dysthymic depressions. Psychiatric Clinics of North America, 2, 595 (1979). 